\title{
Algumas considerações sobre a saúde mental dos funcionários públicos
}

A relação entre trabalho e sofrimento psíquico é abordado a partir de uma experiência de trabalho psicoterápico com funcionários públicos. $\mathrm{O}$ caso brasileiro é aqui analisado num momento em que ocorrem profundas transformações políticas neste âmbito.

"Sempre que se quiser saber como vai a saúde mental dentro de uma determinada instituiçāo pública, basta observar quantas vezes por ano seus dirigentes reformam suas salas, divisórias, paredes, cortinas..." Ao fazer tal ironia, um antigo funcionário ministerial talvez ignorasse estar destacando um importante indicador para uma pesquisa deste tema.

\section{Ezio Flavio Bazzo \\ CRP 01-Brasília / Dr. em Psicologia Clínica}

[O poder é um exercício de atordoamento, uma precaução contra a ociosidade e suas angústias]

Pascal

O que dizer de verdadeiramente importante, num breve e ligeiro artigo sobre uma temática que envolve dois dos mais reverenciados tabus dentro da sociedade brasileira: o funcionalismo público e a saúde mental? $E$, ainda mais, quando as fontes disponiveis sobre o assunto em questão são praticamente inexistentes ou, então, não tão dig nas de honorabilidade?

Como a idéia fundamental é apenas trazer para discussão o problema relacional Trabalho versus Saúde Mental e colocar em evidência as dificuldades mais graves que os funcionários públicos vêm sofrendo dentro de seus locais de trabalho, não me resta outra alternativa senão valer-me, para estas consideraçōes, por um lado, de minha experiência como psicoterapeuta no interior de uma instituição pública federal, e por outro, da escassa literatura pertinente que dispomos. Espero que os leitores, acostumados à um maior rigor científico, me permitam, pelo menos por esta vez, valer-me de uma linguagem, digamos, jornalística, para tratar de tema tão relevante.

A relação entre trabalho e transtornos mentais, ou entre trabalho e sofrimento psíquico (trabalho em geral), é um assunto que, se até pouco tempo era mantido em sigilo

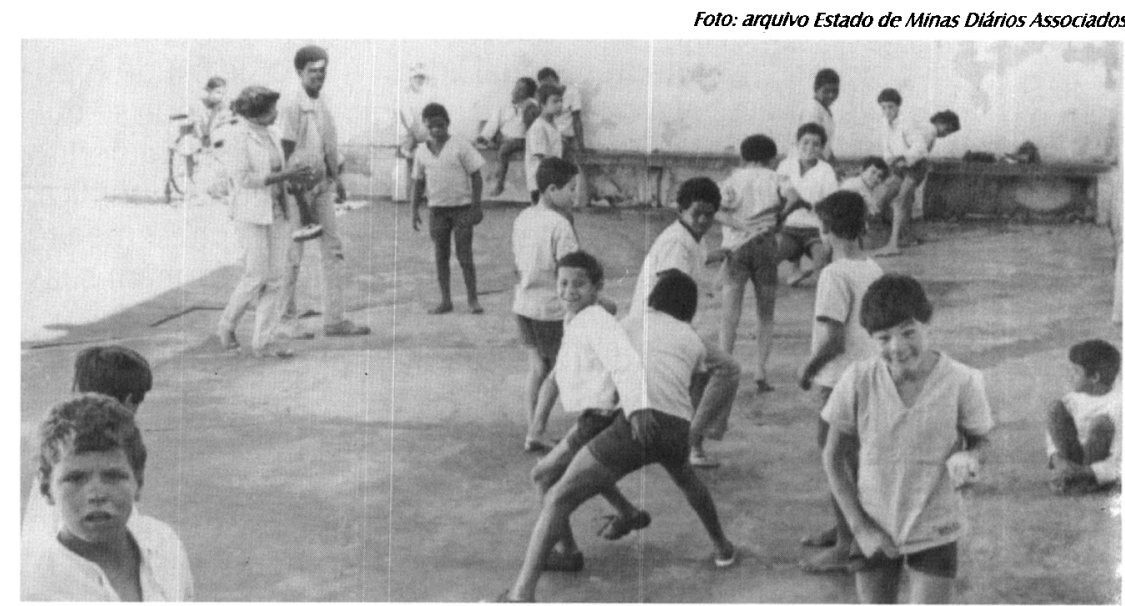

no mundo inteiro, agora começa a ser discutido e encarado, mesmo com todas as dificuldades que a discussão da saúde mental sempre teve que enfrentar. Apesar do número de funcionários que sofrem de transtornos mentais e de doenças psicossomáticas visivelmente relacionadas à organização do trabalho ser imenso, na verdade, ainda existe um preconceito enorme dentro das instituiçōes em se falar e em se tratar de assuntos relacionados à saúde mental. Com medo de serem rotuladas de "loucas" por um psicólogo, por um psiquiatra ou pelos próprios colegas, as pessoas, mesmo as já conscientes de seus conflitos, investem tudo na sua dissimulaçāo e no seu ocultamento, o que, freqüentemente, as têm desestabilizado e marginalizado ainda mais no universo das relações do trabalho e até mesmo as lançado nas estatísticas dos incapacitados.

Para que se tenha uma idéia da gravidade do que se está falando, um documento da OMS, já em 1985, indicava que 5 
a $10 \%$ da força de trabalho ocupada (na desocupada a situação é sempre mais grave) sofriam de transtornos mentais sérios e que cerca de $30 \%$ sofriam de distúrbios psíquicos de menor gravidade. Mais recentemente, outra fonte dava conta de que nos EEUU, os distúrbios mentais representam hoje a segunda causa de afastamento no trabalho. E é curioso que essa questão não afeta - como se costuma pensar - apenas os funcionários que executam as funções mais simples, pelo contrário, o aumento de $50 \%$ na procura de atendimento psicoterapeuta foi entre os altos executivos.

Mas, em se tratando do Brasil, qual é a situação dos funcionários públicos em relação à saúde mental? Um antigo funcionário ministerial ligado à área de saúde mental costumava ironizar: "sempre que se quiser saber como vai a saúde mental dentro de uma determinada instituição pública, basta observar quantas vezes por semestre ou por ano seus dirigentes reformam suas salas, suas paredes, suas cortinas, etc". Apesar do conteúdo folclórico desta definição, na verdade ela leva em si uma verdade quase clínica. Quem atentar para as reformas, principalmente de divisórias, no interior dos órgão públicos, verá que elas acontecem não apenas esporadicamente, nas mudancas de governo, etc., mas sim, durante os doze meses do ano. E mais, que essa prática não tem apenas o objetivo de desviar dinheiro público - como se costuma pensar -, mas que é, digamos, uma forma inconsciente dos chefes, dos subalternos e de todo o "corpo administrativo" resolver ansiedades, angústias e neuroses relacionadas com suas atividades. Já que não é possível ser o que se $\hat{E}$, nem mudar internamente, no caráter de cada um, muda-se fora. Uma nova sala ou um espaço novo, por mais pueril que pareça, garante ao funcionário público, pelo menos por algum tempo, a sensação de alivio e também, de ser Outro.

Aqueles profissionais que desenvolvem algum tipo de ações de saúde junto aos funcionários públicos observam com facilidade que a situação da saúde mental no âmbito dessa categoria é muito mais grave do que se possa imaginar. Quem tivesse a iniciativa de escrever a história da saúde mental no universo do funcionalismo público brasileiro, digamos, nos últimos $\mathbf{3 0}$ anos, chegaria a dados estarrecedores e não teria dúvidas de que a atual Organização do Trabalho dentro da "máquina pública" é, literalmente, uma máquina a serviço do desprazer, da depressão e da insanidade. E essa realidade pode ser facilmente confirmada, verificando o número de consultas médicas mensais a que cada funcionário comparece ${ }^{2}$. Como é arriscado admitir um distúrbio psíquico, os funcionários recorrem compulsivamente às mais variadas especialidades que, mesmo não "detectando" neles nenhum "mal", pelo menos lhes prescrevem algum tipo de placebo, o que lhes garante uma espécie de desabafo, de desafogo e de alívio. Da ginecologia à oftalmologia, do pneumologista à tomografia, a busca de um atestado de doença faz com que os setores de "benefícios" dessas instituições estejam quase sempre congestionados.

E o que é importante observar a respeito desse "engendramento" de angustiados e de depressivos, é que o bloqueio mental que uma organização insana de trabalho provoca no funcionário - como afirma Dejours - é quase sempre a causa principal de suas doenças psicossomáticas. A falta geral de planejamento no interior das instituições públicas, por exemplo: a alta rotatividade dos chefes (sempre nomeados de maneira política e nepotista); a falta de nexo entre a capacitação dos funcionários e o trabalho que realmente desenvolvem; a falta de critérios para nomear ou exonerar pessoas; a dissimetria brutal entre Uns funcionários e Outros; a falta de um plano de cargos e salários que equalize os rendimentos; a luta por um poder (phalo) imaginário que é inconscientemente fomentada entre os funcionários; o fato dos setores de Recursos Humanos terem como função máxima apenas a execução da folha de pagamento, isso tudo, somado à prática de corrupção freqüentemente presente nos assuntos administrativos que envolvem dinheiro, se por um lado impossibilita que o funcionário sinta prazer e realizaçāo no trabalho, por outro funciona como uma espécie de veneno fulminante que age diretamente sobre sua saúde mental.

Apesar de parecer estranho relacionar a corrupção dentro das instituições públicas com os problemas psicológicos de seus funcionários, na verdade, os profissionais que prestarem atenção a essa questão, identificarão com freqüência em seus clientes, essa vinculação. O fato do sujeito trabalhar numa 
instituição onde os signos mais elementares da corrupção estão por todas as partes e assim mesmo ele ter que silenciar, fazer-se de bobo, fingir acreditar que os colegas que enriquecem de um dia para outro realmente estão "herdando" riquezas de seus familiares, "ganhando na loteria", fazendo "consultorias" extras, etc., isto já é um primeiro passo para a confusão mental. Depois, dependendo de sua personalidade, esse funcionário pode ir aos poucos entrando em total estado de angústia, sem saber como relacionar-se, tanto com a instituição a que faz parte, como com o colega corrupto. Execrá-lo ou admirá-lo? Denunciá-lo ou entrar no jogo? Perder as esperanças na realização profissional ou conformar-se com a idéia de que só se realizam aqueles que fazem parte do esquema das propinas.

Mas o que é verdadeiramente curioso, é que a corrupçāo não atinge apenas a saúde mental daqueles funcionários que, apesar de estarem fora do esquema de negociatas ilícitas, sabem, assistem e são até usados como despistes pelos corruptos. $\mathrm{Na}$ verdade, os próprios corruptos assim como os corruptores vão aos poucos apresentando sinais indisfarçáveis de instabilidade emocional, de angústias neuróticas e mesmo de insanidade mental. A energia investida para ocultar, disfarcar, negar ou racionalizar seus atos ilícitos os prostram mais cedo ou mais tarde. Independentemente da ética e da moral que possa envolver essa questão, 0 que nos interessa salientar, aqui, é que nas instituicōes onde a corrupção e a impunidade são fatos que ocorrem com freqüência, 0 que é destruída, antes de qualquer outra coisa, é a possibilidade do trabalho ser experimentado como fonte de prazer.

E essa questão do trabalho ser experimentado como fonte de prazer, apesar de parecer, para alguuns, uma visão romântica e idealizada da escravidão, foi a premissa fundamental tanto do ideário marxista, como anarquista, e inclusive, começa a ser resgatada agora pelos capitalistas ${ }^{3}$. Não evidentemente, porque tenham, de uma hora para outra, "aberto o coração para os proletários do mundo", mas porque começaram a entender que um funcionário triste, deprimido, angustiado, psicologicamente descompensado, produz menos, causa problemas, dá prejuízo, acaba sendo um fardo para seus grandes projetos de produtividade. É por isso que os funcionários mais conscientes e os trabalhadores em geral, começam a interpretar os "progressos trabalhistas" e os "benefícios" conquistados e concedidos a eles dentro do mundo do trabalho, não mais como uma "dádiva" do capital, mas sim de uma maneira mais crítica, através de uma visão menos imediatista, admitindo até, que nesses "progressos" e nesses "benefícios" possam estar introjetadas formas novas, sutis e perversas de exploração.

É evidente que o estresse, a angústia e a depressão que se manifestam com tanta freqüência entre os funcionários públicos não são, necessariamente, conseqüências apenas de sua relaçāo com o trabaIho ou dos conflitos vividos dentro dele. $O$ trabalho é, em muitos casos, apenas o detonador desses transtornos. Observamos que quando o funcionário já era uma pessoa conflitiva, insegura e neurótica antes de ingressar no serviço público, sucumbe às relaçōes insanas de trabalho com muito mais facilidade e é empurrado rapidamente para a doença. E, neste ponto, o que é importante notar, é que, provavelmente, se as relações de trabalho, ao invés de insanas, fossem gratificantes, se as pessoas sentissem prazer no trabalho, ao invés de desgosto, se conseguissem crescer profissionalmente, ao invés de perder sua auto-estima, as partes problemáticas de sua personalidade poderiam até ser amenizadas e o trabalho até funcionar como algo terapêutico ${ }^{4}$. Mas, como vão aos poucos entendendo que é impossivel transformar o trabalho em algo gratificante, correm em debandada para a aposentadoria, mesmo sabendo que lá também é outro campo minado de carências, de abandono e de solidāo ${ }^{5}$. Numa pesquisa que realizamos com 280 funcionários públicos aposentados de uma determinada instituicão federal, eles responderam à pergunta "Por que você tomou a iniciativa de aposentar-se?", da seguinte maneira: $55 \%$ por desânimo, desmotivaçāo e desilusão com os serviços públicos; $9 \%$ por problemas de saúde e $36 \%$ para gozar desse direito.

Uma questão que tem sido discutida com freqüência é até onde as crises sócio-políticas e mesmo administrativas interferem, diretamente ou não, na sanidade mental dos funcionários públicos. Na nossa opinião, a interferência é direta e brutal. $O$ desempre-
3. Wilhelm Reich, em seu estudo de 1937 sobre a Democracia Natural do Trabalho, afirmava: "O trabalho é uma atividade biológica fundamental, a qual, como a vida inteira, está baseada nas pulsaçōes prazerosas (...). O trabalho de milhões de assalariados de todo o mundo nāo /hes proporciona nenhum prazer nem nenhum tipo de satisfação biológica. Se basela essenclalmente no trabatho obrigatório. Este se caracteriza pelo fato de que se opõe à necessidade biológica de prazer do trabalhador. o trabalhador nāo tem interesse no produto de seu trabalho, portanto, o trabalho é desagradível e está desprovido de prazer. O trabalho, baseado na coerção, não Importa de que classe, e nào no prazer, nào é somente insatisfatório biologicamente, mas também muito pouco produtivo economicamente". Reich, $W$. (1980).

4. "A alegria da vida aplicada ao trabalho é um elemento essenctal e absolutamente indispensável para a restruturacáo do homem destinada a fazer do escravo do trabalho que era, o amo da produçāo. Quando se restabeleça a relacào imediata entre o homem e o produto de seu trabalho, o trabalhador assumirá prazerosamente a responsabilldade sobre ele" Idem, $p .20$ 
5. "A aposentadoria e a velhice se confundem na marginalidade. Há, segundo a OMS, pessoas aposentadas que, apesar de ainda nāo terem atingido o limite cronológico da velhice, 60/65, por conta de seu rompimento com a força de trabalho, sajo considerados inativos. Na nossa sociedade, por nāo produzirem formalmente (com contratos de trabalho, etc.) perdem a importâncla social $e$, como tal, a sociedade preconceituosa as estigmatiza como faz com o veIho que é considerado inútil, incapaz, doente, coitado". Da Silva, $M$. H. (1996).

6. Já em 1917, quando o Dr. Freud publicava suas "Nocōes introdutórias sobre Psicanálise", o primeiro número do jornal "Mental hrgiene" trazia um artigo alertando para o fato de que "pacientes desempregados apresentam sérios problemas, agrupados em três classificacoóes: personalidades paranóides, personalidades inadequadas e instabilidade emocional". Codo, W. (1988).

7. E aqui nos surpreendemos novamente frente à discussajo levantada por Basaglia: ficarinertes sob o pessimismo da razão ou desafiar as contingencias da realidade através do otimismo da prática? "E é somente assim que podemos mudar o mundo, senāo ficaremos sempre escravos doe ditadores, doe militares e dos médicos". Basaglla, F. (1982).

\section{Referências Bibliográficas}

go, por exemplo. A perda do trabalho, às vezes, faz mais estragos na saúde mental do sujeito do que a perda de uma pessoa querida ${ }^{6}$. O desemprego, além do problema econômico que representa, gera insegurança, fobias, paranóias e, por fim, o desespero. Uma pesquisa da John Hopkins University, mostrou que a cada 1,4 percentual de desemprego, 26.440 morrem do coracāo, 1.540 cometem suicídio e 5.520 se internam em clínicas e hospitais psiquiátricos. Mas, apesar destes dados serem estarrecedores, apesar de indicarem uma crise psicossocial praticamente nunca antes registrada, o que se observa, por parte do Estado, da sociedade organizada e principalmente por parte dos trabalhadores da saúde, é uma apatia e uma indiferença, no mí nimo, incompreensível, o que nos leva a admitir, que o tabu da doença mental está, inclusive entre nós, mais presente do que nunca. Se para os governos, por um lado, não é conveniente preocupar-se com essa questão, pois, para atuar nessa área, ter-seia que evidenciar todos os disparates administrativos, econômicos e burocráticos que são sistematicamente escamoteados, para os funcionários, por outro, é menos conveniente ainda, pois correm o risco de serem taxados de malucos, de loucos, de doentes mentais e até mesmo de perderem o emprego. Entre os dois lados, paradoxalmente, estamos nós, nós que apesar de nos dizermos Trabalhadores da Saúde Mental, não temos sido, até agora, muito dados a fazer pesquisas nesta área, o que nos têm obrigado a orientar nosso trabalho e nossa práxis profissional em fontes superficiais ou nem sempre confiáveis.

Bidouze, R. (1979). Les fonctionnaires: sujets ou citovens. Paris, Éditions Sociales.

Chassagne, A. e Montracher, G. (1978). La fin du travail. Paris, Éditions Stock.

Codo, W. (1988). Saúde mental e trabalho: uma urgência prática. Psicologia, Clência e Profissão. Ano 8, no 2.

Córdova, A. e Quesada, F. (1979). EI proceso de trabajo y su relacion con la salud mental. México. Revista Salud Mental, $n^{\circ} 4$.

Crozier, M. ( 1983). A sociedade bloqueada. Brasilla. Ed. Universidade de Brasilia.

Da Silva, M. H. (1996) A pré-aposentadoria (pontos crítcos). Brasílla. Apostila da ENAP.

Dejours, C. (1987). A loucura do trabalho. Sāo Paulo, Ed. Oboré.

Fahrat, E. (1986). O paraíso do vira-bosta. Sāo Paulo, T. A. Queiroz Editor.

Lopes, F. A Saúde Mental no dia-a-dia do Trabalho. São Paulo. Gazeta Mercantil (25-11-96).
Os próprios sindicatos e as associaçōes de trabalhadores, que poderiam estar à frente de um programa nacional de conscientização dessa questão, parecem estar por demais ocur pados com a própria sobrevivência para enxergar o avanço silencioso e gradual das doenças mentais entre o funcionalismo. Quando se preocupam com as condiçōes de trabalho dos funcionários públicos, estão quase sempre voltados para questões burocráticas, de salários, de beneficios ou, quando induem a saúde em suas pautas, pensam apenas na saúde física, acidentes de trabalho, indenizaçōes, etc. A saúde mental, com todos os seus sinais, é negada também por eles, como se ninguém, absolutamente ninguém, quisesse arriscar-se a entrar no espaço tenebroso da depressão, da melancolia e do sofrimento psíquico, o que nos leva a pensar que, no nosso pais, pelo menos a curto prazo, só mesmo um "milagre" poderia estancar e mur dar essa realidade.

Como as instituiçōes, em geral, com seus respectivos dirigentes, estão minadas de equívocos administrativos, de irregularidades financeiras, de desvios éticos, de comprometimentos desleais, de sigilos compartilhados, etc., pensar numa maneira imediata de intervir, tanto com formas preventivas como terapêuticas no que diz respeito aos transtornos mentaisé quase uma utopia?. Talvez, o que de melhor se possa fazer neste momento, é desmistificar o assunto, trazer a temática da saúde mental para o cenário da discussāo política, lançar a responsabilidade desse problema sobre as costas do Estado, dos administradores, dos sindicatos, dos própriosfuncionários e, claro, dos milhares e milhares de psicólogos e de psiquiatras que se fecham cada dia mais em seus consultórios ou em suas cátedras, comose nāo tivessem absolutamente nada a ver com isso.

OIT/OMS. (1984). Comitê misto de medicina do trabalho, Genebra.

Pfister, T. (1988). La républlque des fonctionnaires. Paris, Albin Michel.

De la Fuente, R. ( 1982). Revista Salud Mental, vol. 2. México. Reich, W. ( 1980). La plaga emocional en el trabajo. Barcelona. Ediciones Sintesis.

Santos, O. de A. (1995). Ninguém morre de trabalhar (o mito do estresse). (1995). São Paulo. Texto Novo.

Schwartzenberg, R. G. ( 1978). O estado espetáculo. Rio de Janeiro. DIFEL.

Silva, F. S. (1988). Os vínculos entre condições de trabalho e saúde mental. Psicologia, Ciência e profissão. Ano 8, $n^{\circ} 2$. Tannenbaum, F. (?). A filosofia do trabalho. Rio de Janeiro. LIvraria Clássica Brasileira.

Vorcaro, A. R. ( 1988). De que adoecem e morrem os trabaIhadores? Psicologia, Clência e Profissão. Ano 8, n 2. 